\title{
Cryopreservation of Ram Semen in Extenders Containing Soybean Lecithin as Cryoprotectant and Hyaluronic Acid as Antioxidant
}

\author{
A Najafi ${ }^{1}$, MH Najafi ${ }^{2}$, Z Zanganeh ${ }^{2}$, M Sharafi ${ }^{2,3}$, F Martinez-Pastor $^{4}$ and H Adeldust ${ }^{2}$ \\ ${ }^{1}$ Department of Animal Science, College of Agriculture, University of Tabriz, Tabriz, Iran; ${ }^{2}$ Department of Animal Science, College of Agriculture \\ and Natural Resources, University of Tehran, Karaj, Iran; ${ }^{3}$ Department of Embryology, Reproductive Biomedicine Research Center, Royan Institute \\ 1 for Reproductive Biomedicine, ACECR, Tehran, Iran; ${ }^{4}$ INDEGSAL and Molecular Biology, University of León, León, Spain
}

\begin{abstract}
Contents
A soybean lecithin-based extender supplemented with hyaluronic acid (HA) was assayed for effectiveness to improve the quality of frozen-thawed ram semen. HA has not been tested yet in an extender containing soybean lecithin for freezing ram semen. Thus, the aim of this study was to analyse the effects of soybean lecithin at $1 \%$ or $1.5 \%$ along with $\mathrm{HA}$ at $0,0.5$ and $1 \mathrm{mg} \mathrm{ml}^{-1}$ in a Tris-based extender on the motion characteristics, membrane integrity (HOST), viability, GSH peroxidase (GSH-PX) activity, lipid peroxidation and acrosomal status after freezing-thawing. Semen was collected from four Mehraban rams during the breeding season and frozen in the six lecithin $\times$ HA extenders. The extender containing $1.5 \%$ lecithin supplemented with no HA yielded higher total motility $(52.5 \% \pm 1.6)$, viability $(55.8 \% \pm 1.6)$ and membrane integrity $(44.5 \% \pm 1.7)$, but the effects of the lecithin concentration did not reach signification. Linearity-related parameters, ALH, $\mathrm{BCF}$, lipid peroxidation, GSH-PX activity, morphology and acrosomal status were not affected by the extender composition. In general, adding HA significantly decreased sperm velocity $\left(1 \mathrm{mg} \mathrm{ml}^{-1} \mathrm{HA}\right)$, total motility (only with $1.5 \%$ lecithin), viability $\left(1 \mathrm{mg} \mathrm{ml}^{-1} \mathrm{HA}\right.$ for $1 \%$ lecithin; both concentrations for $1.5 \%$ lecithin) and membrane integrity. In conclusion, adding HA to the freezing extender supplemented with soybean lecithin failed to improve quality-related variables in ram semen. Increasing the lecithin content could have a positive effect, but further studies are needed.
\end{abstract}

\section{Introduction}

Sperm cryopreservation is the elective technique for indefinitely storing spermatozoa, allowing to maintain genetic pools and to achieve optimal utilization of the sperm doses through artificial insemination (AI) and in vitro fertilization (IVF) (Demianowicz and Strzezek 1995). In sheep, an increase in the efficiency of cryopreservation and in the application of the cryopreserved doses would allow to increasing productivity and the performance of genetic improvement programmes, and to controlling communicable diseases (facilitated by natural mating) (Holt 1997).

The plasma membrane of ram spermatozoa has a particular composition which makes cryopreservation difficult (Watson 1995). The ratio of polyunsaturated/ saturated fatty acids is relatively high and there is a lower cholesterol/phospholipid molar ratio than in other species, increasing the susceptibility to oxidative damage. Oxidative stress subsequently leads to impaired cell function, which results in the loss of sperm motility and mitochondria activity, the activation of apoptotic pathways and an increase of DNA damage, reducing the fertility of the cryopreserved samples (Aitken and Vernet 1998; Purdy 2006;
Sarı̈̈zkan et al. 2009). In addition, since ROS (reactive oxygen species) are physiologically involved in the maintenance of the fertilizing ability and in the capacitation and acrosome reaction of spermatozoa, excessive levels could impair the fertilization capacity by disrupting these pathways (Alvarez and Storey 1982; Baumber et al. 2000).

It has been shown that sperm quality during the freezethawing process can be improved by adding different antioxidants to the semen extender (Atessahin et al. 2008; Zanganeh et al. 2013). In recent years, many substances with antioxidant activity have been tested as supplements in ram semen extenders, such as cysteamine, taurine, trehalose and selenium, in order to improve the postthawing motility, viability and membrane integrity of spermatozoa (Aisen et al. 2002; Uysal et al. 2005). However, there is little information on the use of hyaluronic acid (HA), also called hyaluronan, as a supplement for freezing ram semen (Bucak et al. 2007). Hyaluronic acid is a non-sulfated glycosaminoglycan that is an essential component of the extracellular matrix. It has many properties, such as contributing to cell-to-cell identification, cellular cohesion and growth regulation (Mendoza et al. 2009). Moreover, this molecule can act as an antioxidant (Mendoza et al. 2009), and it is involved in important sperm physiological functions such as motility, capacitation and antioxidant capacity (Erlinger 1995; Rodriguez-Martinez et al. 2001). Some studies have noted that it preserves post-thaw spermatozoa viability and in vitro membrane stability (Pena et al. 2004).

Furthermore, it has been established that the use of egg yolk as a cryoprotectant can cause some problems. For instance, egg yolk compositions vary between batches, and animal origin products represent a potential sanitary risk (Gadea et al. 2004; Sharafi et al. 2009). Egg yolk can be substituted by products of plant origin, such as soybean lecithin, which can be produced in controlled batches and do not convey sanitary risks, while improving the quality and fertility cryopreserved semen (Andrabi 2009; Akhter et al. 2012). Therefore, the purpose of this study was to evaluate the effects of supplementing the freezing extender with different concentrations of lecithin and hyaluronic acid on the quality of ram semen and os parameters related to oxidative stress.

\section{Materials and Methods}

\section{Reagents}

All chemicals were purchased from Sigma (St. Louis, MO, USA) and Merck (Darmstadt, Germany). 


\section{Semen collection, processing and extender preparation}

Ejaculates were obtained from four mature Mehraban rams ( 3 and 4 years of age), of superior genetic merit and proven fertility. A total of 24 ejaculates (six per ram) were collected twice a week from each ram using an artificial vagina, during the breeding season (autumn). The primary criteria for evaluation of sperm were the following: volume of $0.75-2 \mathrm{ml}$; concentration $>3 \times 10^{9} \mathrm{ml}^{-1}$; progressive motility $>70 \% ;<10 \%$ abnormal sperm. To minimize the effect of individual differences, ejaculates were pooled prior to extension.

The basic extender used in this study was composed of $27.1 \mathrm{~g} \mathrm{l}^{-1}$ Tris, $10 \mathrm{~g}^{-1}$ fructose, and $14 \mathrm{~g} \mathrm{l}^{-1}$ citric acid. The osmolarity and $\mathrm{pH}$ of this base extender were set at $320 \mathrm{mOsm} \mathrm{kg}{ }^{-1}$ and 7.2 , respectively. Soybean lecithin (L-a-phosphatidylcholine; Sigma P3644) was added to the basic extender at $1 \%(\mathrm{~L} 1)$ or $1.5 \%(\mathrm{~L} 1.5)(\mathrm{w} / \mathrm{v})$ and glycerol at $7 \%(\mathrm{v} / \mathrm{v})$. The base extender was supplemented either with $0(\mathrm{H} 0), 0.5(\mathrm{H} 0.5)$ or $1 \mathrm{mg} \mathrm{m}^{-1}(\mathrm{H} 1)$ hyaluronic acid (sodium salt; Sigma 53747). Each pooled ejaculate was split between six equal aliquots and extended $\left(37^{\circ} \mathrm{C}\right)$ at a final concentration of $4 \times 10^{8} \mathrm{ml}^{-1}$ with each of the six extenders: HOL1, H0L1.5, H0.5L1, H0.5L1.5, H1L1 and H1L1.5. Extended samples were loaded into $0.25 \mathrm{ml}$ French straws (IMV, L'Aigle, France) and equilibrated at $4^{\circ} \mathrm{C}$ for $2 \mathrm{~h}$. Afterwards, the straws were horizontally frozen in liquid nitrogen vapours (5 $\mathrm{cm}$ above liquid nitrogen) for $12 \mathrm{~min}$, and then plunged into liquid nitrogen for storage (Najafi et al. 2013). For sperm evaluation, straws were thawed individually at $37^{\circ} \mathrm{C}$ for $30 \mathrm{~s}$ in a water bath. Sperm evaluation was performed on all semen samples immediately after thawing.

\section{Evaluation of spermatozoa after thawing \\ Sperm motility}

To evaluate sperm motility and motion parameters, we used a computer-assisted sperm motility analysis system (CASA, Version 12 IVOS, Hamilton-Thorne Biosciences, Beverly, MA, USA). The following variables were obtained: Total motility (MOT, \%); progressive motility (PROG, \%); average path velocity (VAP, $\mu \mathrm{m} \mathrm{s}^{-1}$ ); straight-line velocity (VSL, $\mu \mathrm{m} \mathrm{s}^{-1}$ ); curvilinear velocity (VCL, $\mu \mathrm{m} \mathrm{s}^{-1}$ ); amplitude of lateral head displacement $(\mathrm{ALH}, \mu \mathrm{m})$; beat/cross-frequency $(\mathrm{BCF}, \mathrm{Hz})$; straightness (STR, \%); linearity (LIN, \%). At least 200 spermatozoa were assessed in each CASA analysis.

\section{Sperm viability}

Percentages of viable spermatozoa were determined by the eosin-nigrosin staining (Evans and Maxwell 1987). Sperm suspension smears were prepared by mixing a drop of sperm sample with two drops of stain on a warm slide and spreading the stain with a second slide. The viable and non-viable spermatozoa were determined by counting 200 sperm cells under phase-contrast microscopy (CKX41; Olympus, Tokyo, Japan) at 1000X. Spermatozoa displaying partial or complete purple staining were considered non-viable; only cells showing strict exclusion of stain were counted as viable.

\section{Sperm morphology}

Morphological evaluation of spermatozoa was performed by fixing with Hancock's solution (Schäfer and Holzmann 2000). Hancock's solution consisted of $62.5 \mathrm{ml}$ formalin, $150 \mathrm{ml}$ sodium saline solution, $150 \mathrm{ml}$ buffer solution, and $500 \mathrm{ml}$ double-distilled water. Three drops of semen were mixed with $1 \mathrm{ml}$ of Hancock's solution; one drop of this mixture was placed on a microscope slide and mounted with a cover slip. The per cent of abnormal sperm was recorded by counting 200 spermatozoa under phase-contrast microscopy at $1000 \mathrm{X}$.

\section{Hypo-osmotic swelling test}

The hypo-osmotic swelling (HOS) test was used to evaluate the functional plasma membrane of spermatozoa as described by Revell and Mrode (1994). In brief, $25 \mu \mathrm{l}$ of semen was added to $200 \mu \mathrm{l}$ of hypo-osmotic solution $\left(100 \mathrm{mOsm} \mathrm{kg}^{-1}, \quad 57.6 \mathrm{~mm}\right.$ fructose and $19.2 \mathrm{~mm}$ sodium citrate). After $30 \mathrm{~min}$ of incubation, the mixture was homogenized and evaluated under a phase-contrast microscope (CKX41; Olympus, Tokyo, Japan). A total of 200 spermatozoa were counted in at least five different microscopic fields at 400X. The percentage of spermatozoa with swollen and curved tails was recorded as positive to the test (functional membranes).

\section{Malondialdehyde concentration}

Malondialdehyde (MDA) concentration, as a proxy for lipid peroxidation (LPO) in the semen samples, was measured by using the thiobarbituric-acid reactive substances (TBARS) method (Placer et al. 1966). Briefly, $1 \mathrm{ml}$ of the diluted semen $\left(250 \times 10^{6}\right.$ spermatozoa $\mathrm{ml}^{-1}$ ) was mixed with $1 \mathrm{ml}$ of cold $20 \%(\mathrm{w} / \mathrm{v})$ trichloroacetic acid to precipitate protein. The precipitate was pelleted by centrifuging $(960 \times \mathrm{g}$ for $15 \mathrm{~min}$ ), and $1 \mathrm{ml}$ of the supernatant was incubated with $1 \mathrm{ml}$ of $0.67 \%(\mathrm{w} / \mathrm{v})$ thiobarbituric acid in a boiling water bath at $100^{\circ} \mathrm{C}$ for $10 \mathrm{~min}$. After cooling, the absorbance was determined by a spectrophotometer (UV-1200, Shimadzu, Japan) at $532 \mathrm{~nm}$. All MDA concentrations were expressed as

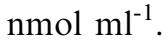

\section{GSH-PX activity assessment}

The GSH-PX activity was determined according to the method proposed by Lawrence and Burk (1976). The reaction mixture consisted of $50 \mathrm{~mm}$ potassium phosphate buffer $(\mathrm{pH}$ 7.0), $1 \mathrm{~mm}$ EDTA, $1 \mathrm{~mm}$ sodium azide $\left(\mathrm{NaN}_{3}\right), 0.2 \mathrm{~mm}$ reduced nicotinamide adenine dinucleotide phosphate (NADPH), $1 \mathrm{EU} \mathrm{ml}^{-1}$ glutathione reductase and $1 \mathrm{~mm}$ GSH. The semen sample $(0.1 \mathrm{ml})$ was added to $0.8 \mathrm{ml}$ of the reaction mixture, incubating at $25^{\circ} \mathrm{C}$ for $5 \mathrm{~min}$ before the initiation of the reaction, induced by the addition of $0.1 \mathrm{ml}$ of a $\mathrm{H}_{2} \mathrm{O}_{2}$ solution (final $\mathrm{H}_{2} \mathrm{O}_{2}$ concentration: $0.25 \mathrm{~mm}$ ). The absorbance at $412 \mathrm{~nm}$ was recorded for $5 \mathrm{~min}$ using a spectrophotometer (UV-1200, 
Shimadzu, Japan). The activity was calculated from the slope of the regression line as micromoles of NADPH oxidized per minute. The blank value was subtracted from each value and the GSH-PX activity was expressed as international units (IU) per g protein (estimated by the Bradford method).

\section{Chlortetracycline staining}

Capacitation and acrosomal status was evaluated by chlortetracycline (CTC) staining (Perez et al. 1996; Gil et al. 2003). Semen was centrifuged $(1000 \times \mathrm{g}$ for $10 \mathrm{~min}$ ) and $3 \mu \mathrm{l}$ of pellet were mixed with $20 \mu \mathrm{l}$ CTC working solution $(2.42 \mathrm{~g}$ Tris, $7.58 \mathrm{~g} \mathrm{NaCl}, 60 \mathrm{mg}$ cysteine and $39 \mathrm{mg}$ chlortetracycline in $100 \mathrm{ml}$ distilled water), $5 \mu \mathrm{l}$ of fixing solution ( $4 \mathrm{ml}$ of $25 \%$ glutaraldehyde in $96 \mathrm{ml}$ of $1 \mathrm{M}$ Tris buffer), and $5 \mu \mathrm{l}$ of mounting solution $(10 \mathrm{ml}$ of $1 \mathrm{M}$ Tris buffer, $90 \mathrm{ml}$ glycerol and $2.46 \mathrm{~g}$ triethylenediamine). Slides were prepared with the mix and evaluated under an epifluorescent microscope (BX51; Olympus, Tokyo, Japan). Two hundred spermatozoa were evaluated and included within one of the following categories; F-pattern (intact), when fluorescence was detected over the whole region of the sperm head; B-pattern (capacitated), when fluorescence was detected in the sperm head except in the post-acrosomal region; and AR-pattern (acrosome-reacted), with no head fluorescence except for a bright band in the equatorial segment.

\section{Statistical analysis}

Data were analysed in the $\mathrm{R}$ statistical environment, using linear mixed-effects models (Team R 2012). The $\mathbf{B}$ mathematical model included main effects (lecithin and HA concentrations) and their interactions. When necessary, multiple comparisons were carried out by using Tukey's correction. Results are shown as mean \pm SEM.

\section{Results}

Results of CASA parameters are shown in the Fig. 1. H0L1.5 extender allowed to obtaining higher percentages of total motility $(52.5 \% \pm 1.8)$, progressive motility $(24.3 \pm 1.5)$, velocity (VAP: $96.8 \pm 2.4 \mu \mathrm{m} \mathrm{s}^{-1}$; VSL: $72.8 \pm 1.1 \mu \mathrm{m} \mathrm{s}^{-1}$; VCL: $173.0 \pm 2.1 \mathrm{~mm} \mathrm{~s}^{-1}$ ) and linearity (LIN: $42.0 \% \pm 0.9$; STR: $75.0 \% \pm 1.6$ ), although effects were not significant $(\mathrm{p}<0.1)$. In general, HA decreased CASA variables, although effects were not always significant. We detected an interaction between lecithin and HA content for total motility (Fig. 1a), with $\mathrm{H} 0$ showing significantly higher values than $\mathrm{H} 0.5$ and H1 when combined with L1.5, whereas HA concentrations were not significantly different when combined with L1. HA had significant effect on the three velocity parameters (Fig. 1c-e) while not showing significant interactions with lecithin. Therefore it was analysed as a main effect, resulting in $\mathrm{H} 0$ showing significantly higher for VCL, VSL and VAP, irrespective of lecithin content. The rest of the parameters were not significantly affected
Fig. 1. Motility parameters assessed by CASA (mean \pm SEM) in samples cryopreserved with both lecithin concentrations (lines) and HA concentrations. Capital letters show significant differences between HA concentrations (overall); Greek letters show significant differences between HA concentrations only for $1.5 \%$ lecithin (no effect on HA for 1\%). No significant effects were found for lecithin concentrations
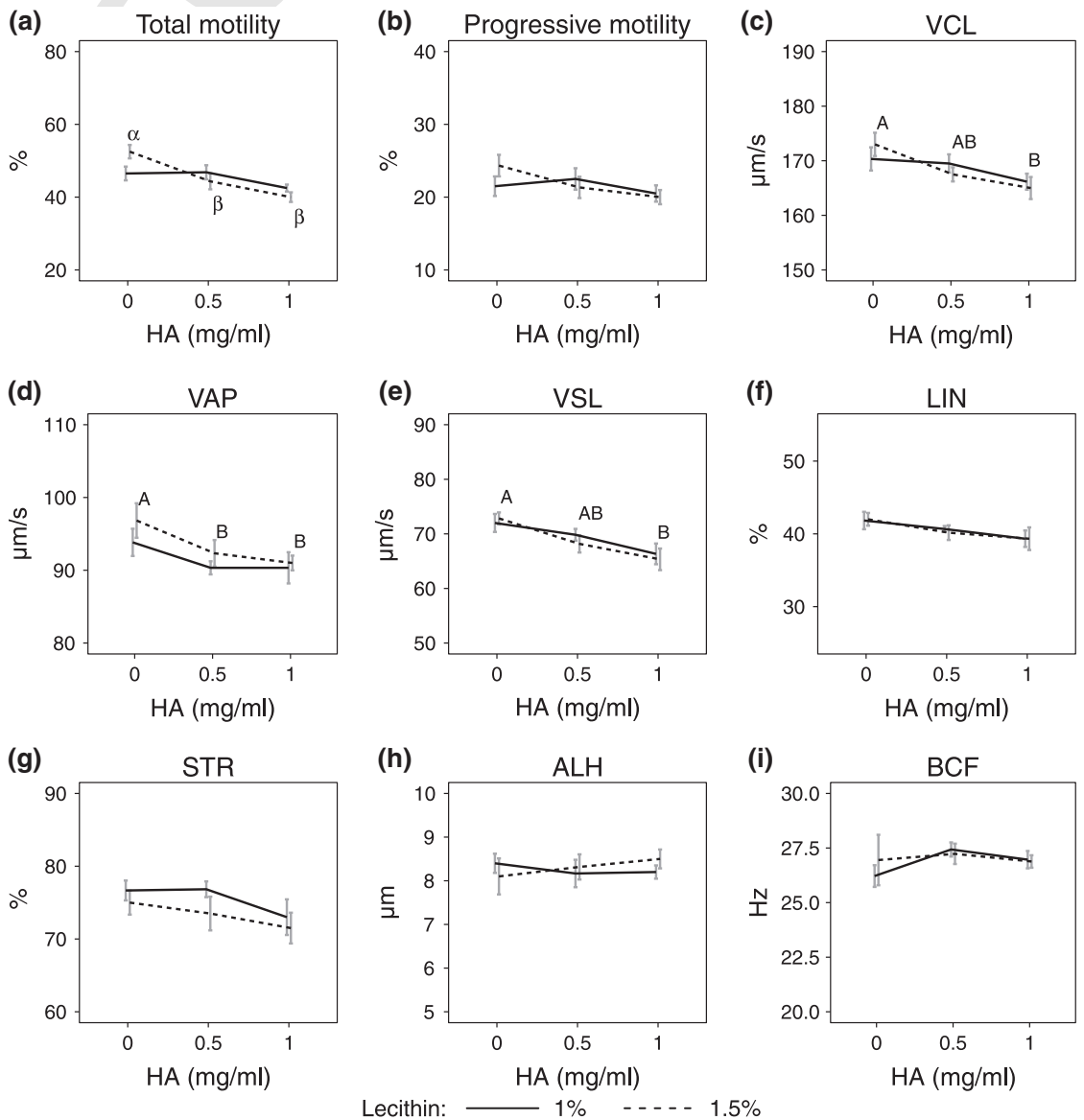
by either lecithin or HA content, although linearity showed a significant linear trend inversely related to HA concentration.

Functionality variables (viability, Fig. 2a, and membrane integrity, Fig. 2b) depended on the HA content, being H0L 1.5 the combination yielding higher values $(55.8 \% \pm 2.0$ and $44.5 \% \pm 1.6$, respectively). In the case of viability, the difference between H0L1 and H0L1.5 was nearly significant $(p=0.055)$. We detected an interaction between lecithin and HA content for viability, resulting in slightly different trends for lecithin $1 \%$ and $1.5 \%$. For the former, viability did not significantly vary between $\mathrm{H} 0$ and $\mathrm{H} 0.5$, whereas for the latter $\mathrm{H} 0$ was significantly higher than $\mathrm{H} 0.5$ and $\mathrm{H} 1$. HOST results were very similar between both lecithin concentrations, and thus we analysed HA as a main effect, resulting in a significantly lower membrane integrity results for $\mathrm{H} 1$ overall (Fig. 2b). Abnormal forms (Fig. 2c) were not significantly affected by the studied factors. Nevertheless, we detected a significant positive linear trend related to HA concentration $(\mathrm{p}=0.046)$.

The rest of the variables were not significantly affected by HA or lecithin content. Variables related to the oxidative stress (GSH peroxidase activity and malondialdehyde concentration) showed small variations between treatments (Table 1). Similarly, the capacitation status or the proportion of spermatozoa with reacted acrosomes were not affected by the composition of the extender (Table 2), with most spermatozoa showing the $\mathrm{B}$ pattern $(59.3 \% \pm 0.4)$, related to a capacitated status.

\section{Discussion}

This study perused the effect of hyaluronic acid in the post-thawing quality of ram semen in extenders containing different soybean lecithin concentrations. We have found that, at least in extenders containing soybean lecithin, hyaluronic acid could be detrimental to sperm quality. Additionally, our experiment suggests that using $1.5 \%$ of soybean lecithin could improve sperm quality after thawing, although fertility trials are required to evaluate its practical use.

Hyaluronic acid has been used for sperm selection in several studies (Morrell and Rodriguez-Martinez 2010; Said and Land 2011). In parallel, some studies have found positive effects of this molecule for the refrigerated storage, cryopreservation and incubation of human (Sbracia et al. 1997) and boar spermatozoa (Yeste et al. 2008). These effects were related to the modulation of sperm physiology. Hyaluronic acid binds to sperm receptors, triggering the phosphorylation of intracellular targets in processes related to the dynamics of the oviduct sperm reservoir (Liberda et al. 2006) and capacitation (Yeste et al. 2008) (inducing or delaying it). Moreover, hyaluronic acid has interesting antioxidant properties that are being exploited in different fields (Mendoza et al. 2009). Both aspects, physiological modulation by interaction with sperm receptors and antioxidant properties, make hyaluronic acid an attractive molecule to test as an extender supplement.

However, contrarily to the good results obtained in boar, studies in goat (Mara et al. 2007) and ram (Bucak et al. 2007) have resulted in hyaluronic acid having little or even negative effect in post-thawing sperm quality. Bucak et al. (2007) tested a range of antioxidants, including hyaluronic acid at 0.5 and $1 \mathrm{mg} \mathrm{m}^{-1}$, observing no effects, despite of the increase in sperm quality yielded by some of the other supplements (Bucak et al. 2007). Mara et al. (2007), studying the refrigerated storage of goat semen by adding the antioxidant TEMPOL with and without hyaluronic acid $\left(0.6 \mathrm{mg} \mathrm{ml}^{-1}\right)$, found that the combination, despite increasing motility at $24 \mathrm{~h}$ of storage, decreased the pregnancy rate, although the kidding rate was not significantly affected. Bruemmer et al. (2009) found that increasing levels of hyaluronic acid $\left(0.1\right.$ to $\left.1 \mathrm{mg} \mathrm{ml}^{-1}\right)$ in an equine extender decreased sperm quality, contrarily to findings in boar, arguing that differences between species (e.g., composition of the plasma membrane) could play an critical role in the optimal hyaluronic acid concentration. Although these studies differ on the lipidic cryoprotectant (using egg yolk), our results similarly suggest that hyaluronic acid might be unsuitable for freezing ram semen. However, our most important finding is the interactions found between lecithin and hyaluronic acid concentration for total motility and viability, suggesting that the potential positive effect of $1.5 \%$ lecithin could be abolished by the addition of hyaluronic acid. Therefore, hyaluronic acid, possibly through its interaction with membrane receptors, might drive sperm physiology to a status less suitable for enduring cryopreservation.
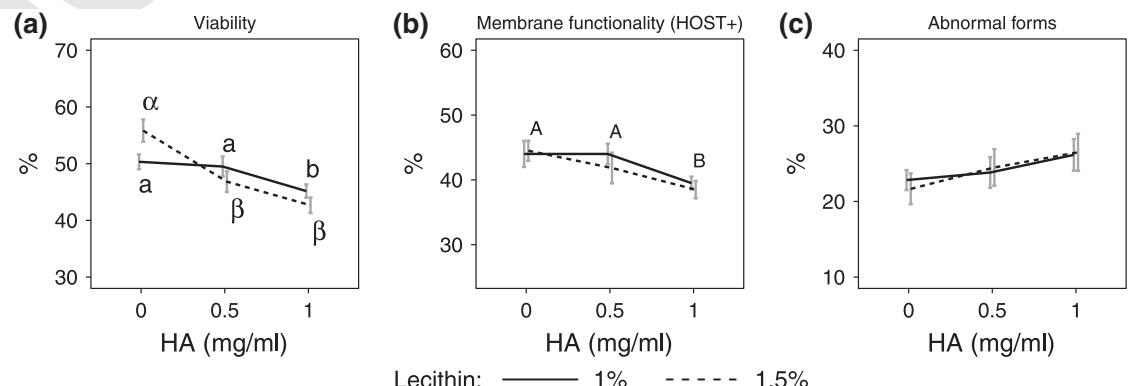

Fig. 2. Results of viability, HOST and morphology assessment (mean \pm SEM) in samples cryopreserved with both lecithin concentrations (lines) and HA concentrations. Capital letters show significant differences between HA concentrations (overall); regular letters show significant differences between HA concentrations only for $1 \%$ lecithin; Greek letters show significant differences between HA concentrations only for $1.5 \%$ lecithin. No significant effects were found for lecithin concentrations 
Table 1. Lipid peroxidation (LPO, showed as malondialdehyde production) and activity of the enzyme GSH peroxidase (GSH-PX) analysed in thawed semen samples frozen using extenders with the different lecithin-hyaluronic acid combinations. Results are shown as means \pm SEM. No significant effects of either treatment were detected

\begin{tabular}{|c|c|c|c|c|c|c|}
\hline $\begin{array}{l}\text { Soybean lecithin } \\
\text { Hialuronic acid }\left(\mathrm{mg} \mathrm{ml}^{-1}\right)\end{array}$ & 0 & $\begin{array}{l}1 \% \\
0.5\end{array}$ & 1 & 0 & $\begin{array}{c}1.5 \% \\
0.5\end{array}$ & 1 \\
\hline LPO (MDA, nmol ml ${ }^{-1}$ ) & $3.9 \pm 0.4$ & $3.3 \pm 0.2$ & $3.7 \pm 0.2$ & $3.5 \pm 0.3$ & $3.4 \pm 0.4$ & $4.0 \pm 0.7$ \\
\hline GSH-PX (UI per g protein) & $27.1 \pm 1.8$ & $27.1 \pm 2.4$ & $28.8 \pm 2.8$ & $26.7 \pm 1.6$ & $27.2 \pm 2.4$ & $29.4 \pm 2.4$ \\
\hline
\end{tabular}

Table 2. Proportion of each CTC staining pattern (F: Uncapacitated; B: Capacitated; AR: Acrosome-reacted) in the samples frozen using the different lecithin-hyaluronic acid combinations. Results are shown as means \pm SEM. No significant effects of either treatment were detected

\begin{tabular}{|c|c|c|c|c|c|c|}
\hline $\begin{array}{l}\text { Soybean lecithin } \\
\text { Hialuronic acid }\left(\mathrm{mg} \mathrm{ml}^{-1}\right)\end{array}$ & 0 & $\begin{array}{l}1 \% \\
0.5\end{array}$ & 1 & 0 & $\begin{array}{c}1.5 \% \\
0.5\end{array}$ & 1 \\
\hline $\mathrm{F}(\%)$ & $14.5 \pm 1.1$ & $14.6 \pm 0.6$ & $13.8 \pm 1.0$ & $15.3 \pm 0.8$ & $14.6 \pm 0.9$ & $13.7 \pm 1.0$ \\
\hline B (\%) & $58.5 \pm 0.9$ & $60.1 \pm 0.7$ & $59.5 \pm 1.3$ & $59.6 \pm 1.2$ & $59.5 \pm 0.9$ & $58.8 \pm 1.3$ \\
\hline AR $(\%)$ & $26.9 \pm 1.7$ & $25.3 \pm 1.0$ & $26.8 \pm 1.0$ & $25.1 \pm 1.5$ & $25.9 \pm 1.2$ & $27.6 \pm 2.1$ \\
\hline
\end{tabular}

Our results on lecithin concentration are in agreement with previous reports on the cryopreservation of ram (Forouzanfar et al. 2010; Emamverdi et al. 2013) and buck (Roof et al. 2012; Salmani et al. 2013) semen. Although our results were not conclusive, they suggest further testing on $1.5 \%$ of soybean lecithin or even higher concentrations, to confirm whether higher postthawing quality can be achieved and if such increase justifies a higher investment in cryoprotectant (Emamverdi et al. 2013). Nevertheless, Del Valle et al. (2012) warned about a possible negative effect of $3.5 \%$ soy lecithin in ram semen cryopreservation.

The plasma membrane integrity of spermatozoa is necessary to maintain sperm functionality in reservoirs within the female reproductive tract. In the present study, H0L1.5 resulted in a more favourable viability result, agreeing with Emamverdi et al. (2013), who showed that an extender with $1.5 \%$ of lecithin resulted in a significantly higher percentage of plasma membrane integrity. Although the precise mechanism by which lecithin exerts its effects on plasma membrane of spermatozoa during freeze-thawing process is not clear, it has been suggested that lecithin and other lipidic supplements protect sperm membrane by stabilization and replacement of phospholipids, thus increasing the tolerance to the freezing process (Quinn et al. 1980; Watson 1981; Forouzanfar et al. 2010).

The plasma membrane of the ruminant spermatozoon is rich in polyunsaturated fatty acids, which increases the susceptibility to lipid peroxidation, resulting in the build-up of MDA (Alvarez and Storey 1989; Aitken et al. 1993). One of our initial hypothesis was that the addition of hyaluronic acid could reduce oxidative stress while helping to maintain the natural antioxidant system of the cryopreserved semen. We can reject this hypothesis, at least in protocols similar to ours, as we did not detect any effect neither on MDA levels - as a marker of oxidative stress - nor in GSH-PX levels, as a marker of the natural antioxidant system. Bucak et al. (2009) also reported that adding hyaluronic acid to a Tris-citrate extender with egg yolk did not have any effect on MDA, GSH, GSH-PX or catalase levels. Nevertheless, they found an increase on vitamin $E$ levels when adding hyaluronic acid at $0.5 \mathrm{mg} \mathrm{ml}^{-1}$. Therefore, hyaluronic acid could have an effect in different concentrations or formulations.

Finally, capacitation was not affected by the treatments. Capacitation includes reorganization of membrane components and onward changes in the intercellular metabolism of the sperm (Bergqvist et al. 2006), which are physiologically necessary for fertilization, but detrimental if they are induced during sperm manipulation or storage. In fact, the cryopreservation is known to induce modifications that can result in a capacitated state (Watson 1995). In our study, most of the thawed spermatozoa were evaluated as capacitated or, worse, acrosome-reacted. Neither hyaluronic acid nor lecithin concentrations could modify this population pattern. Our results agree with previous studies (Sharafi et al. 2009; Najafi et al. 2013; Zanganeh et al. 2013), who reported that cryoprotectants and supplements had no effect on the CTC staining patterns obtained after thawing of sperm cryopreserved in extenders with soybean lecithin as cryoprotectant.

In conclusion, hyaluronic acid was unsuccessful improving the post-thawing quality of ram semen, and, in fact its presence was negative for some variables. Regarding lecithin concentration, its use at $1.5 \%$ could yield more benefits than at $1 \%$, although this issue must be tested in fertility trials.

\section{Acknowledgements}

Felipe Martínez-Pastor was supported by the Ramón y Cajal program (RYC-2008-02560, MICINN, Spain).

\section{Author contributions}

Dr. Adeldust designed and coordinated the study and collected data. Mr. A. Najafi, M.H. Najafi, Z. Zanganeh and M. Sharafi carried out 
the experiments and analyses and collected data. Dr. Martínez-Pastor and Mr. A. Najafi wrote the manuscript and analysed the data. All the authors collaborated revising the manuscript.

\section{Conflict of interest}

None of the authors have any conflict of interest to declare.

\section{References}

Aisen EG, Medina VH, Venturino A, 2002: Cryopreservation and post-thawed fertility of ram semen frozen in different trehalose concentrations. Theriogenology 57, 1801-1808.

Aitken RJ, Vernet P, 1998: Maturation of redox regulatory mechanisms in the epididymis. J Reprod Fertil Suppl 53, 109118.

Aitken RJ, Buckingham D, Harkiss D, 1993: Use of a xanthine oxidase free radical generating system to investigate the cytotoxic effects of reactive oxygen species on human spermatozoa. J Reprod Fertil 97, 441-450.

Akhter S, Ansari MS, Andrabi SM, Rakha BA, Ullah N, Khalid M, 2012: Soyalecithin in extender improves the freezability and fertility of buffalo (Bubalus bubalis) bull spermatozoa. Reprod Domest Anim 47, 815-819.

Alvarez JG, Storey BT, 1982: Spontaneous lipid peroxidation in rabbitm epididymal spermatozoa: its effect on sperm motility. Biol Reprod 27, 1102-1108.

Alvarez JG, Storey BT, 1989: Role of glutathione peroxidase in protecting mammalian spermatozoa from loss of motility caused by spontaneous lipid peroxidation. Gamete Res 23, 77-90.

Andrabi SMH, 2009: Factors affecting the quality of cryopreserved buffalo (Bubalus bubalis) bull spermatozoa. Reprod Domest Anim 44, 552-569.

Atessahin A, Bucak MN, Tuncer PB, Kizll M, 2008: Effects of anti-oxidant additives on microscopic and oxidative parameters of Angora goat semen following the freeze-thawing process. Small Rumin Res 77, 38-44.

Baumber J, Ball BA, Gravance CG, Medina V, Davies-Morel MCG, 2000: The effect of reactive oxygen species on equine sperm motility, viability, acrosomal integrity, mitochondrial membrane potential and membrane lipid peroxidation. J Androl 21, 895-902.

Bergqvist AS, Ballester J, Johannisson A, Hernandez M, Lundeheim N, RodriguezMartinez H, 2006: In vitro capacitation of bull spermatozoa by oviductal fluid and its components. Zygote 14, 259-273.

Bruemmer JE, Wilson CH, Coutino da Silva M, Squires EL, 2009: Effects of hyaluronan supplementation on cryopreserved equine spermatozoa hyaluronan and cryopreserved equine spermatozoa. J Equine Vet Sci 29, 223-228.

Bucak N, Ateşşahin A, Varışlı Ö, Yüce A, Tekin N, Akçay A, 2007: The influence of trehalose, taurine, cysteamine and hyaluronan on ram semen: microscopic and oxidative stress parameters after freezethawing process. Theriogenology $\mathbf{6 7}$, 1060-1067.

Bucak MN, Sarı̈̈zkan S, Tuncer PB, Ulutas PA, Akçadağ Hi, 2009: Effect of antioxidants on microscopic semen parameters, lipid peroxidation and antioxidant activ- ities in Angora goat semen following cryopreservation. Small Rumin Res 81, 90-95.

Del Valle I, Gomez-Duran A, Holt WV, Muino-Blanco T, Cebrian-Perez JA, 2012: Soy lecithin interferes with mitochondrial function in frozen-thawed ram spermatozoa. J Androl 33, 717-725.

Demianowicz W, Strzezek J, 1995: The effect of lipoprotein fraction from egg yolk on some of the biological properties of boar spermatozoa during storage of the semen in liquid state. Reprod Domest Anim 31, 279-280.

Emamverdi M, Zhandi M, Zare Shahneh A, Sharafi M, Akbari-Sharif A, 2013: Optimization of ram semen cryopreservation using a chemically defined soybean lecithin-based extender. Reprod Domest Anim 48, 899-904.

Erlinger R, 1995: Glycosaminoglycans in porcine lung: an ultrastructural study using cupromeromic blue. Cell Tissue Res 81, 473-483.

Evans G, Maxwell WMC, 1987: Handling and examination of semen. In: ????? ????? (eds), Salamon's artificial insemination of sheep and goat. Butterworths Pty Ltd, ?????, Australia, pp. 93-104.

Forouzanfar M, Sharafi M, Hosseini S, Ostadhosseini S, Hajian M, Hosseini L, Abedi P, Nili N, Rahmani H, NasrEsfahani M, 2010: In vitro comparison of egg yolk-based and soybean lecithinbased extenders for cryopreservation of ram semen. Theriogenology 73, 480-487.

Gadea J, Sellés E, Marco MA, Coy P, Matás C, Romar R, Ruiz S, 2004: Decrease in glutathione content in boar sperm after cryopreservation: Effect of the addition of reduced glutathione to the freezing and thawing extenders. Theriogenology 62, 690-701.

Gil J, Lundeheim N, Söderquist L, Rodríguez-Martínez H, 2003: Influence of extender, temperature, and addition of glycerol on post-thaw sperm parameters in ram semen. Theriogenology 59, 1241-1255.

Holt WV, 1997: Alternative strategies for the long-term preservation of spermatozoa. Reprod Fertil Dev 9, 309-319.

Lawrence RA, Burk RF, 1976: Glutathione peroxidase activity in selenium-deficient rat liver. Biochem Biophys Res Commun 71, 952-958.

Liberda J, Manaskova P, Prelovska L, Ticha M, Jonakova V, 2006: Saccharidemediated interactions of boar sperm surface proteins with components of the porcine oviduct. J Reprod Immunol 71, 112-125.

Mara L, Dattena M, Pilichi S, Sanna D, Branca A, Cappai P, 2007: Effect of different diluents on goat semen fertility. Anim Reprod Sci 102, 152-157.

Mendoza G, Prieto J, Real R, Perez M, Merino G, Alvarez A, 2009: Antioxidant profile of hyaluronan: physico-chemical features and its role in pathologies. Mini Rev Med Chem 9, 1479-1488.
Morrell JM, Rodriguez-Martinez H, 2010: Practical applications of sperm selection techniques as a tool for improving reproductive efficiency. Vet Med Int 2011, ????-????.

Najafi A, Zhandi M, Towhidi A, Sharafi M, Akbari Sharif A, Khodaei Motlagh M, Martinez-Pastor F, 2013: Trehalose and glycerol have a dose-dependent synergistic effect on the post-thawing quality of ram semen cryopreserved in a soybean lecithin-based extender. Cryobiology 66, 275-282.

Pena AI, Barrio M, Becerra JJ, Quintela LA, Herradon PG, 2004: Zona pellucida binding ability and responsiveness to ionophore challenge of cryopreserved dog spermatozoa after different periods of capacitation in vitro. Anim Reprod Sci 84, 193-210.

Perez LJ, Valcarcel A, de las Heras MA, Moses DF, Baldassarre H, 1996: In vitro capacitation and induction of acrosomal exocytosis in ram spermatozoa as assessed by the chlortetracycline assay. Theriogenology 45, 1037-1046.

Placer ZA, Cushman LL, Johnson BC, 1966: Estimation of product oflipid peroxidation (malonyl dialdehyde)inbiochemical systems. Anal Biochem 16, 359-364.

Purdy PH, 2006: A review on goat sperm cryopreservation. Small Rumin Res 63, 215-225.

Quinn P, Chow P, White I, 1980: Evidence that phospholipid protects ram spermatozoa from cold shock at a plasma membrane site. J Reprod Fertil 60, 403-407.

Revell SG, Mrode RA, 1994: An osmotic resistance test for bovine semen. Anim Reprod Sci 36, 77-86.

Rodriguez-Martinez H, Tienthai P, Suzuki K, Funahashi H, Ekwall H, Johannisson A, 2001: Involvement of oviduct in sperm capacitation and oocyte development in pigs. Reprod Suppl 58, 129-145.

Roof DJ, Bowley S, Price LL, Matsas DJ, 2012: Comparison of two commercial extenders for cryopreservation of goat semen without sperm washing. Theriogenology 77, 412-420.

Said TM, Land JA, 2011: Effects of advanced selection methods on sperm quality and ART outcome: a systematic review. Hum Reprod Update 17, 719-733.

Salmani H, Nabi MM, Vaseghi-Dodaran H, Rahman MB, Mohammadi-Sangcheshmeh A, Shakeri M, Towhidi A, Shahneh AZ, Zhandi M, 2013: Effect of glutathione in soybean lecithin-based semen extender on goat semen quality after freeze-thawing. Small Rumin Res 112, 123-127.

Sarı̈̈zkan S, Bucak MN, Tuncer PB, Ulutaş PA, Bilgen A, 2009: The influence of cysteine and taurine on microscopic-oxidative stress parameters and fertilizing ability of bull semen following cryopreservation. Cryobiology 58, 134-138.

Sbracia M, Grasso J, Sayme N, Stronk J, Huszar G, 1997: Hyaluronic acid substantially increases the retention of motility in 
cryopreserved/thawed human spermatozoa. Hum Reprod 12, 1949-1954.

Schäfer S, Holzmann A, 2000: The use of transmigration and Spermac ${ }^{\mathrm{TM}}$ stain to evaluate epididymal cat spermatozoa. Anim Reprod Sci 59, 201-211.

Sharafi M, Forouzanfar M, Hosseini SM, Hajian M, Ostadhosseini S, Hosseini L, Abedi P, Nili N, Rahmani HR, Javaheri AR, 2009: In vitro comparison of soybean lecithin based-extender with commercially available extender for ram semen cryopreservation. Int J Fertil Steril 3, 149-152.

Team R, 2012: R: A Language and Environment for Statistical Computing. $\mathrm{R}$ Foundation for Statistical Computing, Vienna, Austria, 2007. ISBN 3-90005107-0.
Uysal O, Bucak MN, Yavas, I, Varis, li O, Gürcan IS, 2005: Evaluation of ram sperm frozen with various taurine concentrations. Int Vet J 82, 1059-1061.

Watson PF, 1981: The roles of lipid and protein in the protection of ram spermatozoa at $5 \mathrm{C}$ by egg-yolk lipoprotein. $\mathrm{J}$ Reprod Fertil 62, 483-492.

Watson PF, 1995: Recent developments and concepts in the cryopreservation of spermatozoa and the assessment of their postthawing function. Reprod Fertil Dev 7, 871-891.

Yeste M, Briz M, Pinart E, Sancho S, Garcia-Gil N, Badia E, Bassols J, Pruneda A, Bussalleu E, Casas I, Bonet S, 2008: Hyaluronic acid delays boar sperm capacitation after 3 days of storage at
15 degrees C. Anim Reprod Sci 109, $236-250$

Zanganeh Z, Zhandi M, Zare-Shahneh A,

8,9 Najafi A, Mahdi NM, Mohammadi-Sangcheshmeh A, 2013: Does rosemary aqueous extract improve buck semen cryopreservation? Small Rumin Res 114, $120-125$.

Submitted: 23 Jun 2014; Accepted: 18 Jul 2014

Author's address (for correspondence): F Martinez-Pastor, INDEGSAL and Molecular Biology, University of León, León, Spain. E-mail: felipe.martinez@unileon.es 


\section{Author Query Form}

Journal: RDA

Article: $\quad 12405$

Dear Author,

During the copy-editing of your paper, the following queries arose. Please respond to these by marking up your proofs with the necessary changes/additions. Please write your answers on the query sheet if there is insufficient space on the page proofs. Please write clearly and follow the conventions shown on the attached corrections sheet. If returning the proof by fax do not write too close to the paper's edge. Please remember that illegible mark-ups may delay publication.

Many thanks for your assistance.

\begin{tabular}{|c|c|c|}
\hline Query reference & Query & Remarks \\
\hline 1 & AUTHOR: Please check that authors and their affiliations are correct. & \\
\hline 2 & $\begin{array}{l}\text { AUTHOR: Please provide a current full postal address (including post/zip } \\
\text { code) for the corresponding author. }\end{array}$ & \\
\hline 3 & $\begin{array}{l}\text { AUTHOR: Team } 2012 \text { has been changed to Team R } 2012 \text { so that this citation } \\
\text { matches the Reference List. Please confirm that this is correct. }\end{array}$ & \\
\hline 4 & $\begin{array}{l}\text { AUTHOR: Please check the use of "Uncapacitated" in the Table } 2 \text { caption. } \\
\text { Could it be changed to "Incapacitated"? }\end{array}$ & \\
\hline 5 & $\begin{array}{l}\text { AUTHOR: Please provide state name for reference Evans and Maxwell } \\
\text { (1987). }\end{array}$ & \\
\hline 6 & $\begin{array}{l}\text { AUTHOR: Please provide the editor name(s), publisher location for reference } \\
\text { Evans and Maxwell (1987). }\end{array}$ & \\
\hline 7 & $\begin{array}{l}\text { AUTHOR: Please provide the page range for reference Morrell and } \\
\text { Rodriguez-Martinez (2010). }\end{array}$ & \\
\hline 8 & AUTHOR: Please check all author names in reference Uysal et al. (2005). & \\
\hline 9 & AUTHOR: Please check the journal title in reference Uysal et al. (2005). & \\
\hline
\end{tabular}

